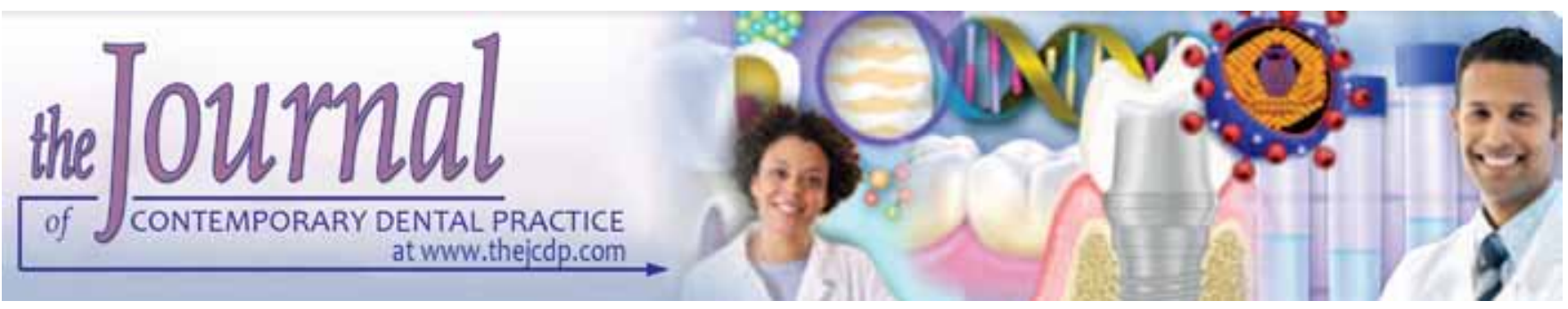

\title{
Cleaning of Root Canal System by Different Irrigation Methods
}

\author{
${ }^{1}$ Mário Tanomaru-Filho, ${ }^{2}$ Lucas Martinati Miano, ${ }^{3}$ Gisselle Moraima Chávez-Andrade \\ ${ }^{4}$ Fernanda Ferrari Esteves Torres, ${ }^{5}$ Renato de Toledo Leonardo, ${ }^{6}$ Juliane Maria Guerreiro-Tanomaru
}

\begin{abstract}
Objective: The aim of this study was to compare the cleaning of main and lateral canals using the irrigation methods: negative pressure irrigation (EndoVac system), passive ultrasonic irrigation (PUI) and manual irrigation (MI).

Materials and methods: Resin teeth were used. After root canal preparation, four lateral canals were made at 2 and $7 \mathrm{~mm}$ from the apex. Root canals were filled with contrast solution and radiographed pre- and post-irrigation using digital radiographic system [radiovisiography (RVG)]. The irrigation protocols were: MI1-manual irrigation [22 $\mathrm{G}$ needle at $5 \mathrm{~mm}$ short of working length-WL]; MI2-manual irrigation (30G needle at $2 \mathrm{~mm}$ short of WL); PUI; EV1-EndoVac (microcannula at $1 \mathrm{~mm}$ short of WL); EV2-Endovac (microcannula at $3 \mathrm{~mm}$ short of WL). The obtained images, initial (filled with contrast solution) and final (after irrigation) were analyzed by using image tool 3.0 software. Statistical analysis was performed by analysis of variance (ANOVA) and Tukey tests (5\% significance level).
\end{abstract}

Results: EV1 and EV2, followed by PUI showed better cleaning capacity than manual irrigation (MI1 and MI2) $(p<0.05)$.

Conclusion: Negative pressure irrigation and PUI promoted better cleaning of main and simulated lateral canals.

Clinical significance: Conventional manual irrigation technique may promote less root canal cleaning in the apical third. For this reason, the search for other irrigation protocols is important, and EndoVac and PUI are alternatives to contribute to irrigation effectiveness.

Keywords: Endodontics, Negative pressure irrigation, Passive ultrasonic irrigation, Root canal cleaning.

How to cite this article: Tanomaru-Filho M, Miano LM, Chávez-Andrade GM, Torres FFE, de Toledo RL, Guerreiro-

\footnotetext{
${ }^{1-6}$ Department of Restorative Dentistry, Araraquara Dental School, UNESP-Univ Estadual Paulista, Araraquara, São Paulo, Brazil
}

Corresponding Author: Mário Tanomaru-Filho, Professor Department of Restorative Dentistry, Araraquara Dental School, UNESP-Univ Estadual Paulista, Rua Humaitá 1680 Centro CEP 14801-903, Araraquara, São Paulo, Brazil Phone: +55-16-3301-6390, e-mail: tanomaru@uol.com.br
Tanomaru JM. Cleaning of Root Canal System by Different Irrigation Methods. J Contemp Dent Pract 2015;16(11):859-863.

Source of support: Nil

Conflict of interest: None

\section{INTRODUCTION}

Infection in the root canal system (RCS) is the main etiological factor to promote pulp and periradicular pathologies, as well as endodontic treatment failure. ${ }^{1,2}$ Root canal irrigation aims to clean and disinfect RCS, by removing organic tissue, smear layer and microorganisms. ${ }^{3-6}$ Its efficacy depends on the irrigation system used, ${ }^{7}$ which should provide a proper flow of the irrigant solution, cleaning the main canal, the isthmus and lateral canals. ${ }^{3}$

Conventional irrigation methods can be effective to clean cervical and middle root canal thirds, and less effective on the apical region, probably because of the root canal diameter, which difficult irrigating solution flow, reducing the hydrodynamic flow. ${ }^{8}$ For these reasons, new devices to improve root canal irrigation are proposed, as ultrasonic and negative pressure irrigation system.

The passive ultrasonic irrigation (PUI) was described by Weller et al. ${ }^{10}$ The term passive describes the noncutting action of the ultrasonically activated file. ${ }^{7}$ It consists in the use of an ultrasonic instrument with small diameter into the root canal filled with irrigating solution. Instrument is activated by ultrasonics device promoting the motion of the fluid motion and cleaning the root canal. ${ }^{3,11}$ Several studies have demonstrated that PUI used at the end of root canal preparation promotes more debris and bacterial removal than manual irrigation (MI) with syringe and needle. ${ }^{3-5,11-14}$

EndoVac (Discus Dental, Culver City, CA, USA) is an irrigation system, based on negative apical pressure, which would be more effective than conventional irrigation. ${ }^{8,15-19}$ This system increases the irrigating solution penetration into the apical root canal third, promoting 
debris removal. ${ }^{18}$ It comprises three components, denominated of master delivery tip (MDT), macro- and microcannula. ${ }^{17}$

Siu et $\mathrm{al}^{20}$ have demonstrated that EndoVac system promotes more effective root canal cleaning than $\mathrm{MI}$, when the microcannula was used either at 1 or $3 \mathrm{~mm}$ short of working length (WL). Similarly, Shin et $\mathrm{al}^{21}$ evaluated in vitro the cleaning efficacy of root canals using EndoVac system and MI with different needles (24 and 30G). Authors concluded that EndoVac promoted the best cleaning of root canal, at the two-thirds evaluated (medium and apical).

Therefore, the aim of this study was to evaluate the cleaning ability of PUI and EndoVac system in comparison to conventional manual irrigation.

\section{MATERIALS AND METHODS}

The methodology used in this study is in accordance with Chávez-Andrade et al. ${ }^{22}$ Forty-eight single-rooted resin teeth (Dental Rossetto Ltda., Arujá, SP, Brazil) were used. These teeth had crowns removed by using a cutting machine Isomet 1000 (Buelher Ltda., Lake Bluff, IL, USA) and their roots were standardized in $14 \mathrm{~mm}$ of length. The root canals were prepared by using MTwo rotary system (VDW, Endodontic Synergy, Munich, Germany). The basic sequence of the system was used (10/0.04, $15 / 0.05,20 / 0.06,25 / 0.06)$, followed by size $25 / 0.07$ file. Working length was determined at $1 \mathrm{~mm}$ short from the apex. Then, 30/0.05, 35/0.04 and 40/0.04 files were sequentially used for all of the WL, to standardize the apical preparation. The root canals were irrigated with $2 \mathrm{ml}$ of distilled water between each file change with a $5 \mathrm{ml}$ syringe (Ultradent Products Inc., South Jordan, USA) and 27G needle EndoEze Irrigator (Ultradent Products Inc., South Jordan, USA).

After instrumentation, four simulated lateral canals, two in the middle and two in the apical third, were made in each root (labial and lingual surfaces), at 2 and $7 \mathrm{~mm}$ short from the apex, by using $0.20 \mathrm{~mm}$ cylindrical drills (Undercut Burs, Union Tool Co., Pluritec, SP, Brazil). A contrast solution (Meglumine sodium diatrizoate, 76\% Pielograf, BerliMed SA, Madrid, Spain) thickened with propylene glycol and bismuth oxide at the proportion of 1:1:1 was prepared and delivered into root canals. Digital periapical radiographs were taken (Kodak RVG 6100 Digital Radiography System, Marne-la-Vallée, France) of all specimens using Spectro 70X Eletronic dental X-ray (Dabi Atlante Inds. Ltda., Ribeirão Preto, SP, Brazil), at $70 \mathrm{kVp}, 8 \mathrm{~mA}$, and 0.4 seconds of exposure. A special device was made to standardize the exposures, with a focus-sensor distance of $11 \mathrm{~cm}$. Therefore, the uniformity of the filling of the main and simulated lateral canals by the contrast solution was confirmed. The specimens were put in a glass flask filled with a silicon-based impression material (Zetaplus, Zhermack, Badia Polesine (RO), Italy) and stored until the experiment.

The specimens were randomly divided into five experimental groups according to irrigation protocols, as shown in Table 1. After 24 hours, the irrigation protocols were performed according to each group. Distilled water was used as irrigant solution in all groups.

In MI1 group, the irrigation was performed with syringe and 22G needle (Endo-Eze Tips, Ultradent Products Inc., South Jordan, USA) positioned at $5 \mathrm{~mm}$ short from the WL and simultaneous aspiration. In MI2 group, irrigation was performed with syringe and 30G needles (NaviTip irrigation, Ultradent Products Inc., South Jordan, USA) at $1 \mathrm{~mm}$ short from the WL and simultaneous aspiration similarly to MI1 group.

In PUI group (intermittent flow) was performed with irrigant solution activated with a size 25 ultrasonic tip (smooth wire) (VDW, Endodontic Synergy, Munich, Germany) placed at $1 \mathrm{~mm}$ short from the WL. Passive ultrasonic irrigation was performed using a piezoelectric device with oscillate at frequency of $30 \mathrm{kHz}$ (CVDent 1000, CVDentus, CVD Vale, São José dos Campos, SP, Brazil). The irrigant solution was delivered into root canal with syringe and $30 \mathrm{G}$ needle MI. The irrigation period was divided as follows: $2 \mathrm{ml}$ of solution in 30 seconds MI, 20 seconds PUI, $1 \mathrm{ml}$ of the solution in 20 seconds $\mathrm{MI}$, 20 seconds PUI and then $2 \mathrm{ml}$ of the irrigant in 30 seconds MI, according with previous studies. ${ }^{1,22}$

In EV1 and EV2 groups, the irrigation was performed with the EndoVacsystem, as follows (modified technique) ${ }^{23}$ : two cycles of macroirrigation were executed with $3 \mathrm{ml}$ of the solution using the macrocannula delivered at $4 \mathrm{~mm}$ short of WL in 30 seconds for each cycle $(60$ seconds in total), followed by 2 cycles of microirrigation during 60 seconds. Each cycle of microirrigation was performed with $3 \mathrm{ml}$ of the solution, during 30 seconds of each cycle (final volume $=12 \mathrm{ml}$ ). In EV1 group, the first cycle of microirrigation was performed with the microcannula

Table 1: Division of the experimental groups

\begin{tabular}{|c|c|c|c|c|}
\hline Groups & $\begin{array}{l}\text { Final irrigation } \\
\text { protocol }\end{array}$ & $\begin{array}{l}\text { Total time and } \\
\text { volume }\end{array}$ & $D$ & $n$ \\
\hline MI1 & $\begin{array}{l}\text { Syringe and } 22 \mathrm{G} \\
\text { needle }\end{array}$ & 2 minutes and $5 \mathrm{ml}$ & $5 \mathrm{~mm}$ & 8 \\
\hline MI2 & $\begin{array}{l}\text { Syringe and } 30 \mathrm{G} \\
\text { needle }\end{array}$ & 2 minutes and $5 \mathrm{ml}$ & $1 \mathrm{~mm}$ & 8 \\
\hline PUI & PUI (\#25) & 2 minutes and $5 \mathrm{ml}$ & $1 \mathrm{~mm}$ & 8 \\
\hline EV1 & EndoVac & 2 minutes and $12 \mathrm{ml}$ & $1 \mathrm{~mm}$ & 8 \\
\hline EV2 & EndoVac & 2 minutes and $12 \mathrm{ml}$ & $3 \mathrm{~mm}$ & 8 \\
\hline
\end{tabular}

G: Group; MI: Manual irrigation; PUI: Passive ultrasonic irrigation; EV: EndoVac; D: Distance of the needle/ultrasonic tip/microcannula short from the working length; $\mathrm{N}$ : Number of specimens 


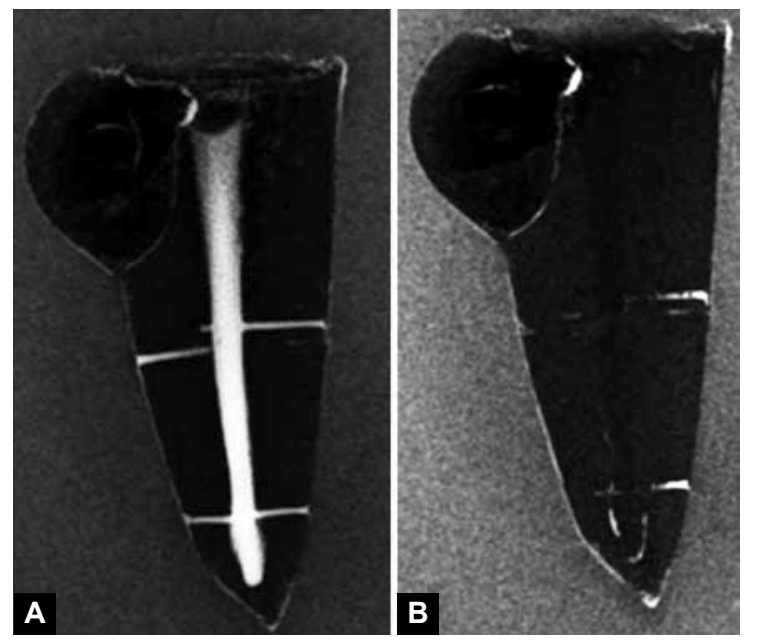

Figs $1 A$ and $B$ : Radiographic image of a evaluated specimen: (A) complete filling with the radiopaque solution and (B) after the protocol of irrigation

placed up to $1 \mathrm{~mm}$ short from the WL without motion; during the second cycle movements of introduction and removal. In EV2 group, irrigation protocol was performed similarly to GIV, except for the penetration distance of the microcannula, which was placed at $3 \mathrm{~mm}$ short from the WL.

Next, new digital radiographs were taken according to the technique of image standardization for the evaluation of the cleaning of main canal and simulated lateral canals. These images were transferred to Image Tool 3.0 software (The University of Texas Health Science Center, San Antonio, Texas, USA) to measurement the areas of main canal and simulated lateral canals (completely filled by the contrast solution) and after irrigation (contrast solution remanent) which were delimited by a previously trained operator. The measurements were obtained in $\mathrm{mm}^{2}$ and the percentage of cleaning was calculated for each group. Comparison among groups was performed by analysis of variance (ANOVA) and when necessary by Tukey test, with level of significance set at $5 \%$.

\section{RESULTS}

Initial and final images obtained (Figs $1 \mathrm{~A}$ and $\mathrm{B}$ ). The obtained results are shown in Table 2. There was a

Table 2: Comparison among groups for the main and lateral root canals (mean and standard deviation of the cleaning percentage)

\begin{tabular}{llll}
\hline Groups & Main canal & $\begin{array}{l}\text { Lateral canals } \\
\text { (medium third) }\end{array}$ & $\begin{array}{l}\text { Lateral canals } \\
\text { (apical third) }\end{array}$ \\
\hline MI1 & $83.58( \pm 3.71)^{\mathrm{C}}$ & $67.07( \pm 10.11)^{\mathrm{B}}$ & $54.97( \pm 6.23)^{\mathrm{B}}$ \\
$\mathrm{M} 2$ & $94.54( \pm 2.26)^{\mathrm{B}}$ & $58.67( \pm 18.08)^{\mathrm{B}}$ & $51.93( \pm 24.20)^{\mathrm{B}}$ \\
PUI & $97.49( \pm 1.65)^{\mathrm{AB}}$ & $73.41( \pm 18.22)^{\mathrm{AB}}$ & $77.53( \pm 18.63)^{\mathrm{A}}$ \\
EV1 & $98.95( \pm 0.93)^{\mathrm{A}}$ & $91.19( \pm 9.68)^{\mathrm{A}}$ & $95.00( \pm 6.92)^{\mathrm{A}}$ \\
EV2 & $98.09( \pm 1.35)^{\mathrm{A}}$ & $88.61( \pm 8.87)^{\mathrm{A}}$ & $95.49( \pm 4.16)^{\mathrm{A}}$ \\
\hline
\end{tabular}

Different letters in the same column indicate statistically significant differences $(p<0.05)$. G: Group; MI: Manual irrigation; PUI: Passive ultrasonic irrigation; EV: EndoVac significant statistical difference between MI1 and the other groups $(\mathrm{p}<0.05)$ in the removal of the contrast solution from the main canal; however, MI2 and PUI obtained similar results ( $p>0.05)$ (Table 2). In the simulated lateral canals, both at the medium and apical third, PUI, EV1 and EV2 showed the higher cleaning when compared to MI1 and MI2 ( $<<0.05)$, according to Table 2.

\section{DISCUSSION}

The simulated lateral canals were made in resin teeth, as already described, ${ }^{22-24}$ with $0.20 \mathrm{~mm}$ of diameter, according to other studies which used resin blocks artificial teeth and natural teeth. ${ }^{5,22,25}$ The radiological contrast solution was thickened with propylene glycol and bismuth oxide to provide consistency and radiopacity, ${ }^{22,26}$ allowing radiographic analysis.

The analysis was performed using digital radiographs according to previous studies. ${ }^{24,27,28}$ The digital radiograph enables an image of quality comparable to conventional radiograph ${ }^{29}$ showing as advantage the standardization and manipulation of images using several tools. ${ }^{27}$ The analysis of radiographic images was performed by Image Tool 3.0 software, enabling measurements in $\mathrm{mm}^{2}$, in the pre- and post-irrigation images. The use of softwares and tools to evaluate different irrigation protocols have already been used in previous studies. ${ }^{22,26,28,30,31}$

The root canal cleaning using various irrigation methods in comparison to manual irrigation has been studied. Howard et $\mathrm{al}^{32}$ observed a similar cleaning capacity, at 2 and $4 \mathrm{~mm}$ from $\mathrm{WL}$, for three irrigation techniques, such as EndoVac, PiezoFlow and irrigation with needle (Max-i-Probe). Dhingra et $\mathrm{al}^{7}$ evaluated the effect of PUI on dentin debris removal from root canals and concluded that PUI is better than MI with syringe.

Mendonca et $\mathrm{al}^{8}$ showed that in the apical region, there was no difference in the debris or smear layer removal using MI and EndoVac. Abarajithan et $\mathrm{al}^{33}$ compared the cleaning provided by either the EndoVac or MI, demonstrating that the cleaning of the apical third is significantly better with EndoVac, which agrees with Kumar et $\mathrm{al}^{19}$ and the present study.

Saber Sel et $\mathrm{al}^{16}$ compared MI, PUI, EndoVac and other irrigation protocols, regarding to smear layer removal in the cervical, medium, and apical thirds of root canals, using SEM and score systems. The results did not show difference between PUI and MI, demonstrating that PUI was not able to completely remove the smear layer from the apical third of root canal. However, final irrigation with EndoVac resulted in better removal of the smear layer than with PUI or MI. Ribeiro et $\mathrm{al}^{34}$ evaluated the debris and smear layer removal in flattened root canals using SEM after the use of different irrigation protocols. Although none of the protocols of irrigant completely 
removed the debris and smear layer, PUI and EndoVac removed more debris than the other manual techniques, similarly to this present study, where PUI and EndoVac provided greater removal of the contrast solution.

Thomas et $\mathrm{al}^{31}$ evaluated the canal isthmus debridement efficacy of a new modified EndoVac irrigation protocol in comparison with EndoVac (EV), PUI and MI. The results showed that EV and PUI performed better than the MI, and are in agreement with this study. Faria et $\mathrm{al}^{35}$ evaluated the efficacy of EndoVac, PUI and conventional needle irrigation $(\mathrm{CNI})$ in $\mathrm{Ca}(\mathrm{OH})_{2}$ removal from root canal, and concluded that none of the techniques completely removed the $\mathrm{Ca}(\mathrm{OH})_{2}$ from root canals. There was no difference between EndoVac and PUI, but these techniques removed more $\mathrm{Ca}(\mathrm{OH})_{2}$ than the $\mathrm{CNI}$. Using similar methodology, Chávez-Andrade et $\mathrm{al}^{22}$ evaluated the efficacy of IUP and manual irrigation (MI) in cleaning of simulated root canals and concluded that IUP with intermittent flow provided better cleaning of simulated lateral canals in the apical third, when compared to MI.

Passive ultrasonic irrigation (intermittent flow) was also evaluated regarding to its effect on the dissolution of bovine pulp tissue of simulated lateral canals $(0.20 \mathrm{~mm}$ of diameter) at the apical third of root canal in epoxy resin models. The results obtained showed the greatest effect of pulp tissue dissolution by PUI, exhibiting a significant difference in the comparison with other irrigation systems including the non-activation of the irrigant solution, which suggests that this technique promotes the irrigation penetration into accessory canals, and consequently a greater cleaning of the apical third of root canals. ${ }^{25}$

In the present study, the different irrigation protocols evaluated were effective in the removal of contrast solution of the root canal (above $83 \%$ ). Middle third presented cleaning between 58 and $91 \%$, with difference between the groups, as in the apical third (51-95\%) where MI was less effective than the other protocols. It is in accordance with others studies that evaluated PUI and EndoVac in comparison with MI. ${ }^{16,18,21,22}$ The irrigation of apical third is an important procedures during endodontic treatment, due apical root area presents the greatest amount of accessory canals and apical ramifications, resulting in greater difficulty for cleaning and disinfection. ${ }^{36}$

The methodology used in this study is an in vitro model reproducible to evaluate protocols, new irrigation devices and techniques developed to improve the cleaning and disinfection of the RCS.

\section{CONCLUSION}

According to the methodology used, EndoVac system and PUI promote better cleaning of main canal and simulated lateral canals at the medium and apical thirds when compared with manual irrigation.

\section{REFERENCES}

1. Guerreiro-Tanomaru JM, Chavez-Andrade GM, FariaJunior NB, Watanabe E, Tanomaru-Filho M. Effect of passive ultrasonic irrigation on enterococcus faecalis from root canals: an ex vivo study. Braz Dent J 2015;26:342-346.

2. Grundling GL, Zechin JG, Jardim WM, de Oliveira SD, de Figueiredo JA. Effect of ultrasonics on Enterococcus faecalis biofilm in a bovine tooth model. J Endod 2011;37:1128-1133.

3. Beus C, Safavi K, Stratton J, Kaufman B. Comparison of the effect of two endodontic irrigation protocols on the elimination of bacteria from root canal system: a prospective, randomized clinical trial. J Endod 2012;38:1479-1483.

4. Blank-Goncalves LM, Nabeshima CK, Martins GH, Machado ME. Qualitative analysis of the removal of the smear layer in the apical third of curved roots: conventional irrigation versus activation systems. J Endod 2011;37: 1268-1271.

5. Castelo-Baz P, Martin-Biedma B, Cantatore G, Ruiz-Pinon M, Bahillo J, Rivas-Mundina B, Varela-Patino P. In vitro comparison of passive and continuous ultrasonic irrigation in simulated lateral canals of extracted teeth. J Endod 2012;38: 688-691.

6. Ghorbanzadeh S, Loodaricheh SA, Samizade S, Loodaricheh S. Irrigants in endodontic treatment. Int J Contemp Dent Medical Reviews 2015;[Epub ahead of print]: ID 030515.

7. Dhingra A, Mangat P, Miglani A, Kalkhande S, Bhullar HK. To evaluate the effect of two passive ultrasonic irrigation methods on removal of dentin debris from root canal systems using computational fluid dynamics study model. Int J Contemp Dent Medical Reviews 2014;[Epub ahead of print]: ID 011214.

8. Mendonca DH, Colucci V, Rached-Junior FJ, Miranda CE, Silva-Sousa YT, da Silva SR. Effects of various irrigation/ aspiration protocols on cleaning of flattened root canals. Braz Oral Res. 2015;29. pii: S1806-83242015000100277. doi: 10.1590/1807-3107BOR-2015.vol29.0082. Epub 2015 Jul 3.

9. Seixas FH, Estrela C, Bueno MR, Sousa-Neto MD, Pecora JD. Determination of root canal cleanliness by different irrigation methods and morphometric analysis of apical third. J Contemp Dent Pract 2015;16:442-450.

10. Weller RN, Brady JM, Bernier WE. Efficacy of ultrasonic cleaning. J Endod 1980;6:740-743.

11. van der Sluis LW, Versluis M, Wu MK, Wesselink PR. Passive ultrasonic irrigation of the root canal: a review of the literature. Int Endod J 2007;40:415-426.

12. Al-Jadaa A, Paque F, Attin T, Zehnder M. Acoustic hypochlorite activation in simulated curved canals. J Endod 2009; 35:1408-1411.

13. Halford A, Ohl CD, Azarpazhooh A, Basrani B, Friedman S, Kishen A. Synergistic effect of microbubble emulsion and sonic or ultrasonic agitation on endodontic biofilm in vitro. J Endod 2012;38:1530-1534.

14. Al-Ali M, Sathorn C, Parashos P. Root canal debridement efficacy of different final irrigation protocols. Int Endod J 2012;45:898-906.

15. Haapasalo M, Shen Y, Qian W, Gao Y. Irrigation in endodontics. Dent Clin North Am 2010;54:291-312.

16. Saber Sel D, Hashem AA. Efficacy of different final irrigation activation techniques on smear layer removal. J Endod 2011; 37:1272-1275. 
17. Jiang LM, Lak B, Eijsvogels LM, Wesselink P, van der Sluis LW. Comparison of the cleaning efficacy of different final irrigation techniques. J Endod 2012;38:838-841.

18. Alves DR, Cunha RS, da Silveira Bueno CE, de Alencar AH, de Araujo Estrela CR, dos Santos TO, Estrela C. Antibacterial potential of $2.5 \%$ sodium hypochlorite in distinct irrigation protocols on enterococcus faecalis biofilm. J Contemp Dent Pract 2015;16:340-346.

19. Kumar VR, Bahuguna N, Manan R. Comparison of efficacy of various root canal irrigation systems in removal of smear layer generated at apical third: an SEM study. J Conserv Dent 2015;18:252-256.

20. Siu C, Baumgartner JC. Comparison of the debridement efficacy of the EndoVac irrigation system and conventional needle root canal irrigation in vivo. J Endod 2010;36:1782-1785.

21. Shin SJ, Kim HK, Jung IY, Lee CY, Lee SJ, Kim E. Comparison of the cleaning efficacy of a new apical negative pressure irrigating system with conventional irrigation needles in the root canals. Oral Surg Oral Med Oral Pathol Oral Radiol Endod 2010;109:479-484.

22. Chávez-Andrade GM, Guerreiro-Tanomaru JM, Miano LM, Toledo RL, Tanomaru-Filho M. Radiographic evaluation of root canal cleaning, main and laterals, using different methods of final irrigation. Rev Odontol UNESP 2014;43:333-337.

23. Tanomaru-Filho M, Sant'anna-Junior A, Bosso R, GuerreiroTanomaru JM. Effectiveness of gutta-percha and Resilon in filling lateral root canals using the Obtura II system. Braz Oral Res 2011;25:205-209.

24. Michelotto AL, Moura-Netto C, Araki AT, Akisue E, Moura AA, Sydney GB. In vitro analysis of thermocompaction time and gutta-percha type on quality of main canal and lateral canals filling. Braz Oral Res 2010;24:290-295.

25. Al-Jadaa A, Paque F, Attin T, Zehnder M. Necrotic pulp tissue dissolution by passive ultrasonic irrigation in simulated accessory canals: impact of canal location and angulation. Int Endod J 2009;42:59-65.

26. Guerreiro-Tanomaru JM, Loiola LE, Morgental RD, Leonardo Rde T, Tanomaru-Filho M. Efficacy of four irrigation needles in cleaning the apical third of root canals. Braz Dent J 2013;24:21-24.
27. Bronnec F, Bouillaguet S, Machtou P. Ex vivo assessment of irrigant penetration and renewal during the cleaning and shaping of root canals: a digital subtraction radiographic study. Int Endod J 2010;43:275-282.

28. Tanomaru-FilhoM,Loiola LE,MianoLM,Chávez-AndradeGM, Guerreiro-Tanomaru JM. Influence of apical foramen diameter, design and penetration depth of the needle and irrigating solution flow rate on cleaning and apical extrusion. Rev Odontol UNESP 2014;43:91-97.

29. Kositbowornchai S, Hanwachirapong D, Somsopon R, Pirmsinthavee S, Sooksuntisakoonchai N. Ex vivo comparison of digital images with conventional radiographs for detection of simulated voids in root canal filling material. Int Endod J 2006;39:287-292.

30. Mitchell RP, Yang SE, Baumgartner JC. Comparison of apical extrusion of $\mathrm{NaOCl}$ using the EndoVac or needle irrigation of root canals. J Endod 2010;36:338-341.

31. Thomas AR, Velmurugan N, SmitaS, JothilathaS. Comparative evaluation of canal isthmus debridement efficacy of modified EndoVac technique with different irrigation systems. J Endod 2014;40:1676-1680.

32. Howard RK, Kirkpatrick TC, Rutledge RE, Yaccino JM. Comparison of debris removal with three different irrigation techniques. J Endod 2011;37:1301-1305.

33. Abarajithan $M$, Dham $S$, Velmurugan N, ValerianAlbuquerque D, Ballal S, Senthilkumar H. Comparison of Endovac irrigation system with conventional irrigation for removal of intracanal smear layer: an in vitro study. Oral Surg Oral Med Oral Pathol Oral Radiol Endod 2011;112:407-411.

34. Ribeiro EM, Silva-Sousa YT, Souza-Gabriel AE, SousaNeto MD, Lorencetti KT, Silva SR. Debris and smear removal in flattened root canals after use of different irrigant agitation protocols. Microsc Res Tech 2012;75:781-790.

35. Faria G, Viola KS, Kuga MC, Garcia AJ, Daher VB, De Pasquali Leonardo MF, Tanomaru-Filho M. Effect of rotary instrument associated with different irrigation techniques on removing calcium hydroxide dressing. Microsc Res Tech 2014;77:642-646.

36. Park E, Shen $Y$, Haapasalo M. Irrigation of the apical root canal. Endod Topics 2013;27:54-73. 